\title{
The Electrical Properties of Sub-5-nm Oxynitride Dielectrics Prepared in a Nitric Oxide Ambient Using Rapid Thermal Processing
}

\author{
Z.-Q. Yao, H. B. Harrison, S. Dimitrijev, Member, IEEE, and Y. T. Yeow, Senior Member, IEEE
}

\begin{abstract}
Ultrathin ( $<5 \mathrm{~nm}$ ) dielectric films have been grown on $\langle 100\rangle$ silicon using rapid thermal processing (RTP) in a nitric oxide (NO) ambient. Interface state density, charge trapping properties, and interface state generation during FowlerNordheim electron injection have been investigated. The films grown in NO have excellent electrical properties. These properties are explained in terms of a much stronger and large number of $\mathrm{Si}-\mathrm{N}$ bonds in both the bulk of the dielectric films and at the $\mathrm{Si}^{-\mathrm{SiO}_{2}}$ interface region. The leakage currents are at least three orders of magnitude lower than other reported results for similar thicknesses. The dielectric films grown in NO ambient are viewed as promising technology for ultrathin dielectrics.
\end{abstract}

\section{INTRODUCTION}

G OOD dielectric films are needed for tunnel dielectric of EEPROMs and as gate oxides of MOSFETs amongst many other applications. It has been found that the electric field induced leakage current and interface state density increase in conventional thin oxides after electrical stress, the effect is becoming much more serious with decreasing oxide thickness [1]-[3]. To obtain a high-quality oxide, thermal nitridation of thin $\mathrm{SiO}_{2}$ in ammonia was proposed to replace the conventional thermal $\mathrm{SiO}_{2}$ for reasons such as improved dielectric integrity and hot-carrier reliability due to the incorporation of nitrogen at the $\mathrm{Si}_{-} \mathrm{SiO}_{2}$ interface [4]-[6]. On the other hand, the nitrided films were reported to show degraded mobility due to the "heavy" nitridation [4], [7], [8] and increased electron trapping due to the incorporation of hydrogen atoms [6]. Recently, $\mathrm{N}_{2} \mathrm{O}$ was proposed and used as an alternative for oxidation and nitridation [9]-[12]. The resulting films show good electrical characteristics; however they have insufficient nitrogen (only $\sim 1-2$ atom \%) at the dielectric-silicon interface to prevent boron penetration [13]-[15]. We have also found that it is not possible to obtain good quality films below $4 \mathrm{~nm}$ using this gas.

Our group has, for the first time, used $\mathrm{NO}$ as an alternative oxidation ambient to avoid the disadvantages of $\mathrm{NH}_{3}$ and $\mathrm{N}_{2} \mathrm{O}$ [16], [17]. X-ray photoelectron spectroscopy (XPS) results show that the dielectric films grown in NO have higher nitrogen concentration in both the bulk of the film and also at the dielectric-silicon interface. We have also found that the

Manuscript received June 29, 1994; revised September 22, 1994

Z.-Q. Yao, H. B. Harrison, and S. Dimitrijev are with the School of Microelectronic Engineering, Griffith University, Nathan, QLD 4111 , Australia.

Y. T. Yeow is with the Department of Electrical and Computer Engineering, The University of Queensland, St. Lucia, QLD 4072, Australia.

IEEE Log Number 9406932. growth rates in $\mathrm{NO}$ are slow compared to that in $\mathrm{N}_{2} \mathrm{O}$ and $\mathrm{O}_{2}$. This is attributed to the stronger and high concentration of Si-N bond in the NO-grown films. In this paper, we present the electrical properties of these NO-grown films. It is shown that the NO-grown films are superior to $\mathrm{O}_{2}-$ and $\mathrm{N}_{2} \mathrm{O}$ - grown films in terms of leakage current, interface state density, and electrical stress induced degradation. For our $3.2 \mathrm{~nm}$ films the leakage current is at least 3 -order of magnitude lower than that reported for the $\mathrm{NH}_{3}$ - nitrided and pure $\mathrm{SiO}_{2}$ films of the same thickness [18]-[20].

\section{EXPERIMENTAL}

1.4-5.0 $\Omega \mathrm{cm} n$-type (100) silicon wafers were cleaned using both a $\mathrm{H}_{2} \mathrm{SO}_{4} / \mathrm{H}_{2} \mathrm{O}_{2}$ solution and RCA cleaning process. The wafers were then washed in $1 \% \mathrm{HF}$ for 60 seconds immediately prior to dielectric film growth. The films were grown in an AG610 rapid thermal processing (RTP) unit. The RTP chamber was purged with ultra high purity $\mathrm{N}_{2}$ prior to the introduction of NO. The dielectric films were grown in $99.0 \% \mathrm{NO}$ at $1150^{\circ} \mathrm{C}$ for 1 to 5 minutes. Some wafers were further exposed to $\mathrm{O}_{2}$ at the same temperature. These are referred to as reoxidized samples. Comparison was made with films of approximately the same thickness grown in $\mathrm{O}_{2}$ and $\mathrm{N}_{2} \mathrm{O}$ at $950^{\circ} \mathrm{C}$ for 30 seconds and 300 seconds, respectively. Aluminum gate MOS capacitors (area $=0.01 \mathrm{~cm}^{2}$ ) were fabricated for electrical characterization.

Thicknesses of the dielectric films in this work, including the pure oxides, were measured using ellipsometry with three angles of incidence $\left(60^{\circ}, 65^{\circ}\right.$, and $\left.70^{\circ}\right)$. This method allows for the extracting both the film thickness and the refractive index [21]. An HP4145B semiconductor parameter analyzer and an HP4284A LCR meter were used to obtain currentvoltage $(\mathrm{J}-\mathrm{V})$, high frequency voltage-capacitance $(\mathrm{C}-\mathrm{V})$ and small-signal conductance $(\mathrm{G}-\mathrm{V})$ characteristics of MOS capacitor before and after positive gate bias Fowler-Nordheim constant-current tunneling stress.

\section{RESULTS AND DISCUSSIONS}

The growth rate in NO is found to be very low, at $1150^{\circ} \mathrm{C}$, the thickness appears to saturate at $3.2 \mathrm{~nm}$ within the first 2 minutes [16]. Figs. 1(a) and 1(b) show the high-frequency (100 $\mathrm{kHz}$ ) $\mathrm{C}-\mathrm{V}$ and $\mathrm{J}-\mathrm{V}$ measurement results of the dielectric films grown in $\mathrm{NO}, \mathrm{N}_{2} \mathrm{O}$, and $\mathrm{O}_{2}$. The thicknesses of these films are $3.2 \mathrm{~nm}, 4.0 \mathrm{~nm}$, and $4.8 \mathrm{~nm}$, respectively, with refractive 
TABLE I

The Interface State Densities Before and after Constant Current Stress and Thickness of Different Dielectric Films Grown at Different Conditions

\begin{tabular}{|c|c|c|c|c|}
\hline $\begin{array}{l}\text { sample } \\
\text { labels }\end{array}$ & growth conditions & $\begin{array}{c}\text { film } \\
\text { thickness } \\
\text { (nm) }\end{array}$ & $\begin{array}{l}\text { interface state density } \\
\text { (before stress) } \\
\left(\times 10^{+11} / \mathrm{cm}^{2} \mathrm{eV}\right)\end{array}$ & $\begin{array}{c}\text { interface state density } \\
\text { (after stress) } \\
\left(\times 10^{+11} / \mathrm{cm}^{2} \mathrm{eV}\right)\end{array}$ \\
\hline N_1 & at $1150^{\circ} \mathrm{C}$ in $\mathrm{NO}$ for $1 \mathrm{~min}$. & 3.0 & 2.07 & 2.21 \\
\hline N_2 & at $1150^{\circ} \mathrm{C}$ in $N O$ for $2 \mathrm{~min}$. & 3.1 & 2.03 & 2.37 \\
\hline N5 & at $1150^{\circ} \mathrm{C}$ in $N O$ for $5 \mathrm{~min}$. & 3.2 & 2.14 & 2.40 \\
\hline NN & $\begin{array}{l}\text { at } 1150^{\circ} \mathrm{C} \text { in } \mathrm{NO} \text { for } 5 \mathrm{~min} \\
\& \text { annealed in } \mathrm{N}_{2} \text { for } 1 \mathrm{~min}\end{array}$ & 3.2 & 1.78 & 1.81 \\
\hline NO_1 & $\begin{array}{l}\text { at } 1150^{\circ} \mathrm{C} \text { in } \mathrm{NO} \text { for } 5 \mathrm{~min} \\
\text { \& reoxidized at } 1150^{\circ} \mathrm{C} \text { in } \\
\mathrm{O}_{2} \text { for } 1 \mathrm{~min} \text {. }\end{array}$ & 3.6 & 2.45 & 2.55 \\
\hline NO_2 & $\begin{array}{l}\text { at } 1150^{\circ} \mathrm{C} \text { in } \mathrm{NO} \text { for } 5 \mathrm{~min} . \\
\& \text { reoxidized at } 1150^{\circ} \mathrm{C} \text { in } \\
\mathrm{O}_{\text {, for } 2 \mathrm{~min} \text {. }}\end{array}$ & 3.8 & 3.25 & 3.42 \\
\hline $\mathrm{N}_{2} \mathrm{O}$ & at $950^{\circ} \mathrm{C}$ in $\mathrm{N}_{2} \mathrm{O}$ for $5 \mathrm{~min}$. & $\overline{4.8}$ & 4.12 & - \\
\hline $\mathrm{O}_{2}$ & at $950^{\circ} \mathrm{C}$ in $\mathrm{O}_{2} 30$ seconds & 4.0 & 6.26 & - \\
\hline
\end{tabular}

indices of $1.65,1.50$, and 1.46 . In the case of the oxide film, there is a distortion in its $\mathrm{C}-\mathrm{V}$ curve, similar to what was reported previously [18]. This film also has a much larger current through the dielectric compared to the other two films. The J-V plot is however similar to those published elsewhere for the film grown in $\mathrm{O}_{2}$ with similar thickness [18]-[20]. The $\mathrm{N}_{2} \mathrm{O}$ film has better $\mathrm{J}-\mathrm{V}$ characteristics compared to the oxide, but both this and $\mathrm{O}_{2}$-grown films show a high tunneling current at bias voltage below $1 \mathrm{~V}$. The film grown in NO has very low leakage current compared to the other two films despite the fact that it is the thinnest. It starts to tunnel for a gate voltage $>1.3 \mathrm{~V}$. Its current density is at least 3 orders of magnitude lower than reported results for nitrided and pure oxides of almost the same thickness [18]-[20].

Column 4 in Table I shows the as grown mid-gap interface state densities of different dielectric films measured using the conductance technique [22]. It is seen that the interface state density in the NO samples does not change with growth time. While the midgap interface density of $\sim 2 \times 10^{11} \mathrm{~cm}^{-2} \mathrm{eV}^{-1}$ is one order of magnitude higher than the values expected from thicker electric films used in MOS devices, it is two to three times lower than that seen in ultrathin $\mathrm{N}_{2} \mathrm{O}$ and $\mathrm{O}_{2}$ films. We believe it is a result of slower growth rate which can result in a more "orderly" interface with less silicon dangling bonds and weak oxygen bonds which were believed to form interface states. By annealing in $\mathrm{N}_{2}$ at $1150^{\circ} \mathrm{C}$ for 60 seconds the interface state density is reduced to $1.78 \times$ $10^{11} \mathrm{~cm}^{-2} \mathrm{eV}^{-1}$. In general the interface state density reported here is lower than those reported for dielectrics with the same thickness [18], [23]. It is also known that interface state density increases with decreasing in the dielectric film thickness [23]. We also subjected samples which were grown in $\mathrm{NO}\left(1150^{\circ} \mathrm{C}\right.$ for 5 minutes) to oxidation in $\mathrm{O}_{2}$ at $1150^{\circ} \mathrm{C}$ (labelled as NO_1 and NO_2 in Table I). The measurement shows that the interface state densities of these reoxidized samples increases with increasing reoxidation time. This is consistent with the growth in film thickness which leads to a larger number of

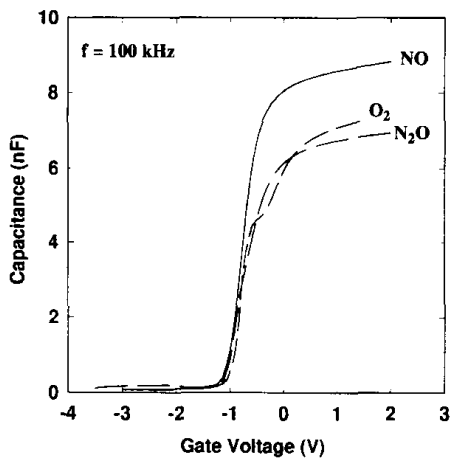

(a)

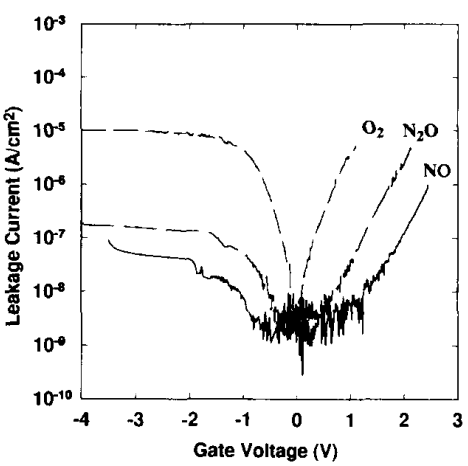

(b)

Fig. 1. (a) The high frequency $(100 \mathrm{kHz}) \mathrm{C}-\mathrm{V}$ characteristics of the dielectric films grown in $\mathrm{NO}$ (at $1150^{\circ} \mathrm{C}$ for $5 \mathrm{~min}$.), $\mathrm{N}_{2} \mathrm{O}$ (at $950^{\circ} \mathrm{C}$ for $5 \mathrm{~min}$.) and $\mathrm{O}_{2}$ (at $1150^{\circ} \mathrm{C}$ for $30 \mathrm{~s}$ ). Area of all the capacitors is $0.01 \mathrm{~cm}^{2}$; (b) the $\mathrm{I}-\mathrm{V}$ characteristics of the dielectric films as shown in (a).

silicon dangling bonds or weak oxygen-silicon bonds at the $\mathrm{Si}-\mathrm{SiO}_{2}$ interface region.

The charge-trapping behavior of various dielectrics was investigated using a positive gate bias Fowler-Nordheim constant-current stressing of $+5 \mu \mathrm{A} / \mathrm{cm}^{2}$. The change in gate 


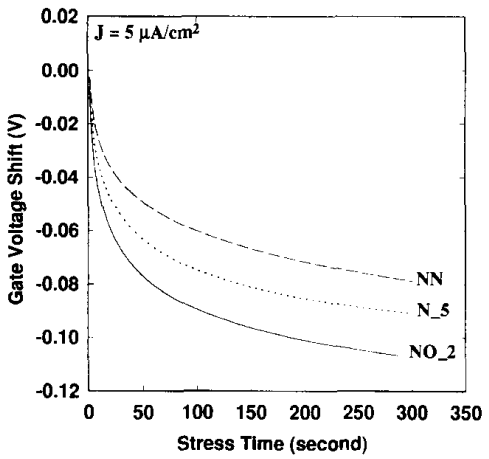

Fig. 2. Gate voltage shift of the dielectric films labeled N_5, NN, and NO_2 (details are in Table I) under a constant-current stressing of $+5 \mu \mathrm{A} / \mathrm{cm}^{2}$ for $300 \mathrm{~s}$.

voltage was monitored during stress, and $\mathrm{C}-\mathrm{V}$ and $\mathrm{G}-\mathrm{V}$ (conductance-voltage) measurement were performed before and immediately after stressing to determine the change in flatband voltage and the generation of the interface states $\left(\Delta D_{\mathrm{it}}\right)$ resulting from the stress. During the stress, the changes of gate voltage $\left(\Delta V_{g}\right)$ are needed to maintain the constant current. The buildup of positive charge during constant-current stress results in a reduction in $V_{g}$ to maintain a constant current. Fig. 2 shows the gate voltage shift, $\Delta V_{g}$, as a function of stress time for an $\mathrm{NO}$ grown (N_5) an NO-grown, $\mathrm{N}_{2}$ annealed (NN), and an NO-grown, reoxidized (NO_2) films. (Samples grown in $\mathrm{O}_{2}$ and $\mathrm{N}_{2} \mathrm{O}$ ambient were found to breakdown almost immediately on applying the constant-current stress). The gate voltages of all these three samples shifted in the negative $V_{g}$ direction indicating positive charge buildup. The results show that all the $\Delta V_{g}$ saturate in about 200 seconds. The highest $\Delta V_{g}$ of about $-0.1 \mathrm{~V}$ is observed for reoxidized sample and the lowest of $-0.07 \mathrm{~V}$ for the nitrogen annealed sample. This agrees with what was stated regarding growth rate and interface states.

It is seen from the results that all the samples grown in an NO environment generally have better electrical characteristics than those grown in either $\mathrm{O}_{2}$ or $\mathrm{N}_{2} \mathrm{O}$ environments. We believe this is due to the higher amount of nitrogen and much stronger Si-N bond in the dielectric films, as we reported previously [16]. Furthermore, we believe that the low growth rate in $\mathrm{NO}$ at $1150^{\circ} \mathrm{C}$ will not only reduce the silicon dangling bonds and weak oxygen bonds in the bulk of the film and at the interface, it will also lead to uniform thickness of the film which we believe is the cause of the superior J-V characteristics of our large area $\left(0.01 \mathrm{~cm}^{2}\right)$ MOS capacitors.

\section{CONCLUSION}

We have studied ultrathin dielectric films grown by RTP in an $\mathrm{NO}$ ambient. It is found that compared to $\mathrm{N}_{2} \mathrm{O}$ and $\mathrm{O}_{2}$ grown films, the NO-grown films have lower interface state density, reduced tunneling current, and improved resistance to constant current stress. The $3.2-\mathrm{nm}$ film we have investigated would be useful as the tunnel dielectric films in EEPROM. We believe that improvement in dielectric properties through the use of RTP in an NO ambient could be incorporated into thicker films grown either in NO or in a different ambient and thus make this process attractive for ultrathin MOSFET dielectric applications in ULSI.

\section{REFERENCES}

[1] K. Naruke, S. Taguchi, and M. Wada, "Stress induced leakage current limiting to scale down EEPROM tunnel oxide thickness," in IEDM Tech. Dig., p. 424, 1988.

[2] P. Olivo, T. N. Ngyyen, and B. Ricco, "High-field-induced degradation in ultrathin $\mathrm{SiO}_{2}$ films," IEEE Trans. Electron Devices, vol. 35, p. 2259 , 1988.

[3] R. Moazzami and C. Hu, "Stress-induced current in thin silicon dioxide films," in IEDM Tech. Dig., p. 92, 1992.

[4] T. Ito, T. Nakamura, and H. Ishikawa, "Advantages of thermal nitride and nitroxide gate films in VLSI process," IEEE Trans. Electron Devices, vol. ED-29, p. 498, 1982

[5] T. Hori, H. Iwasaki, Y. Naito, and H. Esaki, "Electrical and physical characteristics of thin nitride oxides prepared by rapid thermal processing," IEEE Trans. Electron Devices, vol. ED-34, p. 2238, 1987.

[6] T. Hori, H. Iwasaki and K. Tsuji, "Electrical and physical characteristics of ultrathin reoxidized nitride oxides prepared by rapid thermal processing," IEEE Trans. Electron Devices, vol. ED-36, p. 340, 1989.

[7] P. Pan, "Characteristics of thermal $\mathrm{SiO}_{2}$ films during nitridation," $J$. Appl. Phys., vol. 61, p. 284, 1986.

[8] K. S. Krisch, B. J. Gross, and C. G. Sodini, "Positive-charge trapping in nitrided oxide and reoxided nitride gate dielectrics," J. Appl. Phys. vol. 70 , p. $2185,1991$.

[9] H. Fukuda, M. Yasuda, T. Iwabuchi, and S. Ohno, "Novel $\mathrm{N}_{2} \mathrm{O}-$ oxynitridation technology for forming high reliable EEPROM tunnel oxide film," IEEE Electron Device Lett., vol. 12, p. 587, 1991.

[10] J. Ahn, W. Ting, and D.-L. Kwong, "Furnace nitridation of thermal $\mathrm{SiO}_{2}$ in pure $\mathrm{N}_{2} \mathrm{O}$ ambient for ULSI MOS applications," IEEE Electron Device Lett., vol. 13, p. 117, 1992.

[11] W. Ting, G. Q. Lo, J. Ahn, T. Chu, and D.-L. Kwong "Comparison of dielectric wear-out between grown in $\mathrm{O}_{2}$ and $\mathrm{N}_{2} \mathrm{O}$," in IEEE Proc. Reliability Phys. Symp., p. 323, 1991.

[12] A. Uchiyama, H. Fukuda, T. Hayashi, T. Iwabuchi, and S. Ohno, "High performance dual-gate sub-halfmicron CMOSFETs with 6-nmthick nitrided $\mathrm{SiO}_{2}$ films in an $\mathrm{N}_{2} \mathrm{O}$ ambient," in IEDM Tech., Dig., p. 223, 1990 .

[13] A. B. Joshi, J. Ahn, and D.L. Kwong, "Oxynitride gate dielectric for $P^{\dagger}$-polysilicon gate MOS devices, "IEEE Electron Device Lett., vol. 14. p. 560,1993

[14] T. Hori, "Nitrided gate-oxide CMOS technology for improved hotcarrier reliability," in Microelectronic Engineering, vol. 22, p. 245, 1993.

[15] G. W. Yoon, A. B. Joshi, J. Kim, and D. L. Kwong, "MOS characteristics of $\mathrm{NH}_{3}$ nitrided $\mathrm{N}_{2} \mathrm{O}$-grown oxides," IEEE Electron Device Lett., vol. 14, p. $179,1993$.

[16] Z.-Q. Yao, H. B. Harrison, S. Dimitrijev, Y. T. Yeow, and D. Sweatman, "High quality ultra thin dielectric films grown on silicon in a nitric oxide ambient," Appl. Phys. Lett., vol. 64, p. 3548, 1994.

[17] H. B. Harrison, A. Misiura, S. Dimitrijev, D. Sweatman, Z.-Q. Yao, and Y. T. Yeow, "Dielectrics on silicon thermally grown or annealed in a nitrogen rich environment," presented at the spring meeting of MRS in San Francisco, April 1994, published in Digest of Technical Papers.

[18] M. Depas, R. L. Van Meirhaeghe, W. H. Lafere, and F. Cardon, "Electrical characteristics of $\mathrm{Al} / \mathrm{SiO}_{2} / n$-Si tunnel diodes with an oxide layer growth by rapid thermal oxidation," Solid-State Electronics, vol. 37, p. 433, 1994.

[19] S. Naggano, M. Tsukiji, K. Ando, E. Hasegawa, and A. Ishitani, "Mechanism of leakage current through the nanoscale $\mathrm{SiO}_{2}$ layer," $J$. Appl. Phys., vol. 75, p. 3530, 1994.

[20] T. Nguyen, D. A. Carl, S. V. Nguyen, D. M. Dobuzinsky, and J. W. Korejwa, "New leakage mechanism in sub-5 nm oxynitride dielectrics," Appl. Phys. Lett., vol. 63, p. 1972, 1993.

[21] T. S. Chao, W. H. Chen, S. C. Sun, and H. Y. Chang, "Characterizations of oxide grown by $\mathrm{N}_{2}$ O," J. Electrochem. Soc, vol. 140, p. 2905, 1993.

[22] E. H. Nicollian and J. R. Brews, MOS Physical and Technology. New York: Wiley, 1982.

[23] H. Fukuda, M. Yasuda, T. Iwabuchi, S. Kaneko, T. Ueno, and I. Ohdomari, "Process dependence of the $\mathrm{SiO}_{2} / \mathrm{Si}(100)$ interface trap density of ultra thin $\mathrm{SiO}_{2}$ films," J. Appl. Phys., vol. 72, p. 1906, 1992. 